\title{
Pathological Changes in the Central Nervous System in Leprosy.
}

\author{
H. P. LIE.
}

Summary of a Lecture to the Scandinavian Pathological Society, held at Helsingfors in Fuly, 1929.

$\mathrm{D}$ R. LIE commenced by referring to his previous investigations, and reports in this lecture further work which he has carried out on the central nervous system in leprosy.

It was stated that the degeneration in the dorsal columns of the spinal cord was so definite and occurred so frequently, with only small variations, that it might be regarded as characteristic and typical of leprosy. This degeneration differs from that seen in grave diseases associated with cachexia (emaciation), also from that seen in tabes dorsalis (syphilis of the spinal column). Dr. Lie went on to state that his most recent investigations gave support to his former hypothesis that the appearances in the dorsal columns of the spinal cord are due to peripheral nerve changes rather than to the actual attack of the cord by leprosy, although leper bacilli could be demonstrated in the ganglion cells of the spinal cord.

Emphasis was laid upon the degeneration being most pronounced in long standing cases of maculo-anæsthetic leprosy, where it is seldom possible to demonstrate leprotic changes in the spinal ganglia, but where peripheral neuritis has been markedly conspicuous. In nodular leprosy also spinal cord degeneration is found very definitely in all cases which progress slowly, and assume the picture of nerve or anæsthetic leprosy (secondary anæsthetic cases). In such cases, too, leper bacilli are found very frequently in the larger motor ganglion cells of the spinal cord. In cases of nodular leprosy, where there are few signs of nerve involvement, little or no evidence of degeneration of the spinal cord can be discovered, although bacilli can actually be demonstrated in the motor ganglion cells. On the whole, one gets the impression that the ganglion cells suffer less damage from the leper bacilli than one might expect. The author was able to demonstrate leper bacilli in the nuclei of the medulla oblongata, particularly in the nucleus of the facial nerve in a case where there had been no sign clinically 
of any affection of the medulla oblongata, nor of the facial nerve. This demonstration of bacilli in the medulla oblongata has not been previously made to his knowledge. The granular appearance of the bacilli, and the fact that they occur always singly and not in heaps in the ganglion cells, suggest that the leper bacilli cannot multiply in the ganglion cells, but rather become destroyed, while the ganglion cells appear to act as phagocytes.

The author has attempted to trace the degeneration in the dorsal columns of the cord, in a central direction towards the brain, above the medulla oblongata to the thalamus, but it would seem that this degeneration cannot be demonstrated above the nucleus gracilis and nucleus cuneatus. The degeneration must be regarded therefore as affecting only the primary peripheral sensory neuron.

During the last few years the author has undertaken detailed microscopical investigations of five brains from three cases of nodular and two cases of maculo-anæsthetic leprosy, the latter being mentally deficient, in an attempt to find leper bacilli in the brain or its coverings. In the case of the two mentally deficient maculo-anæsthetic lepers it was quite impossible to demonstrate bacilli in the brain or elsewhere. In two of the nodular cases some few bacilli were observed in the pia mater about the infundibulum, also a couple of bacilli in a vessel wall in the thalamus from one case, and in a vessel wall in the middle of the medulla oblongata in the other. In the one case a monocyte full of leper bacilli was found in the middle of a vessel in the pia. Neither of these two cases showed any evidence of mental disease.

All things considered it would appear that the brain, i.e., the ganglion cells of the brain, possess a certain immunity against the leper bacilli, which does not appear to be the case on the part of the ganglion cells in the medulla oblongata, medulla spinalis or the spinal ganglia. In all cases of nodular leprosy there is without any doubt a more or less heavy invasion by leper bacilli of the whole central nervous system including the brain, but it would seem that the physiologically different ganglion cells behave in a different manner towards the leper bacilli, and that the cells of the cerebrum are the most resistant. This may have some significance in our interpretation of the etiology of mental disease occurring in lepers. The author has personal knowledge of nine mentally deficient lepers, five men and four women. Only two of these nine suffered from nodular leprosy in which leper bacilli occur in real abundance. The remaining seven, some of whom were quite light cases, had maculo-anæsthetic 
leprosy. In two cases the mental trouble broke out before the presence of leprosy was detected and cannot therefore be set in etiological relationship to it.

In two cases, as already mentioned, it was not possible to demonstrate leper bacilli in any part of the body, certainly not in the brain. The clinical picture in the nine mental patients was very variable and not uniform as one would be inclined to expect, if the mental disease had been due to invasion of the brain by leper bacilli. One woman had a true melancholia; one man and one woman had mania. The man had paranoiac delusions with the maniacal outburst. One woman had a maniacal-depressive psychosis, while three men had paranoia of medium severity. One woman suffered from dementia, and one man from a mental condition giving an indefinite picture, which probably had an arterio-scleratic basis. None of the mental patients in question showed any symptoms which might be regarded as Korsakow's disease or Korsakow's syndrome.

Taking everything into consideration, the author, therefore, is of the opinion that mental disease in a leper is not directly due to invasion of the brain by leper bacilli, or to their toxins, but that the mental disease, provided that it is not a chance coincidence, is of psychogenic origin. To become a leper has been considered from all times to be one of the greatest misfortunes that can befall anyone, and it is easy to assume that this may have so great an affect upon a predisposed mind as to give rise to a true psychosis.

\section{Literature.}

Leprosy : Summary of Recent Work, No. 17. This is a reprint of the Leprosy sections from the Tropical Diseases Bulletin.

Leprosy in India, No. 2. October, 1929. Issued quarterly by the Indian Council of The British Empire Leprosy Relief Association.

Leprosy in the Far East-A Survey. (Price 2s.) By Dr. R. G. Cochrane.

Leprosy in Europe, the Middle and Near East, and Africa. -A Survey. (Price 2s.) By Dr. R. G. Cochrane.

Leprosy : Symptoms, Diagnosis, Treatment and Provention. (2nd revised edition). (Price 2s.) By Dr. R. G. Cochrane. 